\title{
A MATERIALIDADE DA PRÁTICA EDUCATIVA E AS MOTIVAÇÕES DO PROFESSOR PARA A DOCÊNCIA NO ENSINO SUPERIOR
}

\author{
The Materiality of Educational Practice and the Motivations of the Teacher for the \\ Teaching Practice in Higher Education
}

\author{
Francisco Antonio Machado Araujo ${ }^{1}$ \\ Maria Vilani Cosme de Carvalho ${ }^{2}$
}

\begin{abstract}
Resumo: Este texto é parte dos estudos teóricos e síntese analítica de uma tese doutoral, e objetiva o desenvolvimento de discussões sobre a prática educativa e as motivações do professor para a docência no ensino superior. Para o processo de produção e análise dos dados fez-se uso de dois dispositivos distintos e interligados epistemologicamente, intitulados de sessões de reflexão crítica e unidades analíticas do concreto real. $\mathrm{O}$ estudo ressalta que a docência do ensino superior é um tipo de prática educativa e sua materialidade, de forma ampla, é orientada pela tríade ensino, pesquisa e extensão. Sobre as motivações dos professores investigados para a docência, constatou-se que elas estavam relacionadas às afetações familiares, ao envolvimento com movimentos sociais, à intervenção de ex-professores e à possibilidade de poder colaborar com o desenvolvimento da educação básica. No que se refere ao ingresso no ensino superior, os professores significaram que suas motivações foram produzidas com base em seus anseios de poder contribuir com a qualidade da educação e da formação dos futuros professores da educação básica, além das possibilidades de produzir conhecimento científico na universidade. Os resultados da síntese analítica apresentados nesta discussão sugerem novos estudos, a fim de que se compreendam as particularidades das relações pessoais, profissionais e institucionais do professor do ensino superior, bem como a sua representação na manifestação do desenvolvimento profissional docente.
\end{abstract}

Palavras-chave: Prática educativa. Docência no ensino superior. Narrativa docente.

\begin{abstract}
This text is part of the theoretical studies and analytical synthesis of a doctoral thesis and aims to develop discussions about the educational practice and teacher motivations for teaching in higher education. For the data production and analysis process, two distinct and epistemologically interconnected devices were used, called critical reflection sessions and real concrete analytical units. The study highlights that teaching in higher education is a type of
\end{abstract}

\footnotetext{
${ }^{1}$ Doutor e mestre em Educação pela Universidade Federal do Piauí, Licenciado em História pela Universidade Estadual do Piauí. Graduado em Pedagogia pelo Instituto Superior de Educação Programus, Especialista em História das Culturas Afro-Brasileiras (FTC). Professor Adjunto do Curso de Pedagogia da Universidade Federal do Delta do Parnaíba. Pesquisador do Núcleo de Estudos e Pesquisas Histórico-Críticas em Educação e Formação Humana.(NPESH) E-mail: chiquinhophb@ufpi.edu.br. Orcid: https://orcid.org/0000-0001-8443-6853

${ }^{2}$ Mestre, doutora e pós-doutora em Educação, com área de concentração em Psicologia da Educação, pela Pontifícia Universidade Católica de São Paulo. É professora-pesquisadora da Universidade Federal do Piauí, atuando na área da Educação, em especial sobre temáticas relativas à formação e a prática docente. Líder do grupo de pesquisa (Núcleo de Estudos e Pesquisa Histórico-Críticas em Educação e Formação Humana). (NPESH) Email: vilacosme@ufpi.edu.br. Orcid: https://orcid.org/0000-0002-1675-1808.
} 
educational practice and its materiality, in a broad way, is guided by the triad: teaching, research, and extension. Regarding motivations, from the investigated teachers to the teaching practice, it was found that they were related to family affections, to the involvement with social movements, to the influence of former teachers and the possibility of being able to contribute to the development of basic education. As for entering higher education, teachers meant that their motivations were produced from their desire to be capable of contributing to the quality of education and the formation of future basic education teachers and the possibilities of developing scientific knowledge in the university. The results of the analytical synthesis presented in this discussion suggest new studies to understand the particularities of the personal, professional, and institutional relations of the higher education teacher, as well as their representation in the manifestation of teaching professional development.

Keywords: Teaching Practice. Teaching Practice in higher education. Teaching narrative.

\section{Considerações iniciais}

Se a sociedade é o verdadeiro educador do educador, sua ação se exerce sempre concretamente, isto é, no tempo histórico, no momento pelo qual está passando seu processo de desenvolvimento. Por isso, em cada etapa do desenvolvimento social, o conteúdo e a forma da educação que a sociedade dá a seus membros vão mudando de acordo com os interesses gerais de tal momento.

Vieira Pinto, 2010.

Nas sábias palavras de Vieira Pinto (2010), está implícita a sugestão da sociedade como a primeira e fundamental mediadora da formação do professor, porque é a expressão histórica da humanidade que agrega aspectos à essência do ser humano, como: conceitos, leis, tradições, necessidades, motivos, contradições e sínteses, isto é, cultura. A sociedade representa, na formação do professor do ensino superior, a mediação necessária para a constituição do sentido e significado de docência, da identificação das suas necessidades formativas, bem como do caráter crítico reflexivo na compreensão da própria sociedade como realidade em movimento. Vieira Pinto (2010, p. 112) aprofunda a discussão ao afirmar que:

\footnotetext{
Do feiticeiro da tribo ao pedagogo grego, ao escriba romano, ao clérigo medieval, ao mestre e ao professor universitário de hoje, a genealogia social é a mesma. A constituição da figura do educador, seu status profissional e sua valorização social são efeitos das diferentes etapas pelas quais passa o processo histórico. O nível médio de formação do professorado é um reflexo do nível médio do desenvolvimento social. VIEIRA PINTO (2010, p. 112, grifo nosso).
}

Assim, as maneiras de pensar, sentir e de agir desse professor são sínteses de sua relação com a sociedade, visto que é nesse contexto que se estabelecem novas exigências na formação docente, novas políticas públicas e legislações atualizadas, além da constituição do ser professor. "Por isso é necessário que hoje em dia, quando somos capazes de perceber este fato, preparemos os educadores para se converterem em forças atuantes do desenvolvimento econômico e cultural da sociedade" (VIEIRA PINTO, 2010, p. 113). 
As ideias apresentadas nos fazem refletir sobre questões diversas, por exemplo: Como a sociedade forma o professor do ensino superior? Quem é esse professor? O que particulariza sua atividade docente? Em que contextos e que relações são estabelecidas nessa atividade? Que motivações medeiam seu ingresso na docência no ensino superior? Dessa maneira, na produção de uma síntese que considere alguns desses questionamentos, nosso propósito com este texto é apresentar discussão sobre alguns fundamentos da docência no ensino superior, tendo por base os resultados de uma tese doutoral, bem como discorrer sobre a estrutura do ensino superior e alguns aspectos da legislação que fundamentam seu funcionamento; a função social do professor desse nível de ensino, seus desafios no contexto da sociedade contemporânea, e os processos formativos e reflexões sobre as motivações para o ingresso no ensino superior.

Para isso, estruturamos o texto na seguinte ordem: 1) Considerações iniciais; 2) Percurso metodológico da investigação; 3) A materialidade da docência no ensino superior; 4) Motivações do professor para a docência no ensino superior; e 5) Algumas considerações.

\section{Percurso metodológico da investigação}

O percurso metodológico, trilhado no processo de produção e análise dos dados empregados neste trabalho, foi elaborado, respectivamente, com base em dois dispositivos distintos e interligados epistemologicamente: sessões de reflexão crítica e unidades analíticas do concreto real.

Esse percurso fundamenta-se na ideia de que "investigar o objeto em movimento e compreender as suas determinações, as suas relações e as múltiplas sínteses indicativas de seu desenvolvimento são parte do processo investigativo em que o movimento do conhecimento sobre o objeto se realiza dialeticamente" (ARAUJO; CARVALHO, 2020, p. 185). Nesse fluxo, buscamos desenvolver o movimento que parte do fenômeno em direção à essência e, com isso, apreender as determinações do objeto da investigação. Nos subtópicos a seguir, apresentaremos como esse processo ocorreu.

\subsection{Sessões de reflexão crítica}

As sessões de reflexão crítica foram utilizadas para o processo de produção de dados e identificação das manifestações do fenômeno investigado. Por meio dessas sessões, identificamos três professores para serem colaboradores da investigação (PCIs), então realizamos entrevista memorial, seguida de uma sessão de confrontação e síntese. Conforme Araujo e Carvalho (2020, p. 186):

\footnotetext{
O caráter de criticidade desse dispositivo é dado pela possibilidade de os docentes, ao narrarem partes de sua história de vida, rememorarem fatos e acontecimentos que foram significativos para o seu desenvolvimento profissional, produzirem novas significações sobre essas narrativas e tomarem consciência de determinadas vivências que antes não haviam sido identificadas por eles.
}

No mesmo sentido, Abrahão (2008) reconhece o uso de narrativas como fonte de dados na pesquisa em educação, sobretudo na formação de professores, e ainda afirma que tais narrativas possuem tripla dimensão: 1) como ato de narrar a própria vida pelos docentes, elas são um fenômeno, ou seja, são a própria história contada, a narrativa em si; 2) como parte de um processo investigativo, são um dispositivo científico e 3) são um processo formativo se forem trabalhadas como recurso de ressignificação do vivido, quando oportuniza a reflexão 
crítica dos professores no sentido de produzirem conscientização sobre determinadas vivências e experiências que antes não haviam sido compreendidas.

Com base nessas afirmações, compreendemos que "os fatos, os acontecimentos, as situações narradas pelos professores expressam significações e, por meio delas, conscientizamse das mediações dessas relações para seus processos formativos" (ARAUJO; CARVALHO, 2020, p. 186). Também tomamos como referência as ideias de Vigotski (2010) ao explicar que a palavra é o meio pelo qual o pensamento humano se expressa. Como elemento essencial à linguagem humana, a palavra possui a generalização do pensamento no seu significado. Nesse sentido, o pensamento se realiza pela palavra, que por sua vez, se materializa pelas narrativas dos professores.

Nessa discussão, o que Vigotski (2010) faz é destacar a função social da palavra significada e o seu caráter histórico. Essa função social é caracterizada pela linguagem como "meio de comunicação social, de enunciação, e compreensão" (VIGOTSKI, 2009, p. 11). Por intermédio da palavra, "os professores narram suas trajetórias de vida e vão significando as suas histórias. Essas narrativas são sempre acompanhadas de processo reflexivo" (ARAUJO; CARVALHO, 2020, p. 186-187).

Objetivando apresentar o percurso que mediou os processos de reflexão crítica dos docentes investigados, estruturamos e sistematizamos a produção de dados em três ações sequenciadas: Ação 1 - Seleção dos professores colaboradores da investigação; Ação 2 Entrevista memorial; Ação 3 - Sessão de confrontação e síntese.

Na Ação 1, orientamo-nos pelo objeto e objetivos da investigação, e, com base nisso, definimos tanto os critérios como o processo que identificou três professores do ensino superior para serem colaboradores da investigação: a) ter realizado curso de doutorado e mestrado acadêmico em Educação; b) atuar como docente do ensino superior há mais de 5 anos; c) ter disponibilidade para participar da entrevista exploratória; d) ter disponibilidade para participar das sessões de reflexão crítica; e, por fim, e) apresentar em suas significações produzidas na entrevista exploratória indicativos de que as vivências como docentes no ensino superior mediaram processos de desenvolvimento profissional ${ }^{3}$. Após a seleção, identificamos os professores selecionados pelos seguintes nomes fictícios: Orpheu, Morpheu e Calíope.

$\mathrm{Na}$ Ação 2, norteamo-nos pela ideia de que a memória é fundamento das narrativas dos professores, e realizamos uma entrevista memorial com cada um dos professores em separado, a fim de produzir dados que evidenciassem as vivências desenvolvidas na docência no ensino superior, e as suas significações para o desenvolvimento da sua atividade docente. Nessa ação, os docentes descreveram, informaram, analisaram e produziram sínteses sobre as suas vivências no ensino superior. Abordaram o ingresso na docência, bem como a própria docência no ensino superior, os processos formativos e as transformações ocorridas em suas relações pessoais, institucionais e profissionais.

Durante a Ação 3, conduzimos os professores a situações de reflexão crítica sobre determinadas vivências e experiências que foram narradas durante a entrevista memorial. Eles foram confrontados por meio de questionamentos sobre alguns trechos das narrativas e, com isso, produziram esclarecimentos e aprofundaram discussões que estavam confusas ou haviam sido apresentadas de forma superficial durante a entrevista. Podemos destacar que, nesse momento, tivemos a manifestação de um pensar mais crítico dos docentes, ao produzirem novas

\footnotetext{
${ }^{3}$ Esse critério se associou aos objetivos da tese que originou este texto.
} 
significações sobre seu percurso formativo e novas sínteses a respeito de suas vivências no ensino superior.

\subsection{Unidades analíticas do concreto real}

As unidades analíticas do concreto real consistiram no movimento analítico, pelo qual produziu-se uma rede de conteúdos temáticos estruturados em torno de unidades analíticas, com base nas narrativas produzidas pelos professores. Tais narrativas, articuladas a categorias centrais para produção de síntese teórica, possibilitaram a explicação e o processo de apropriação do objeto desta investigação (ARAUJO, 2019). Esse dispositivo analítico partiu das manifestações do fenômeno presentes nessas narrativas, em direção à construção de nexos que articulam os aspectos singulares, particulares e gerais que caracterizaram as vivências dos docentes com as ações desenvolvidas no estudo realizado na pós-graduação em Educação.

A estruturação do movimento analítico ocorreu da seguinte forma:

a) Identificação de trechos narrativos de significação (TNS), a fim de sistematizar e apreender as manifestações do fenômeno investigado;

b) Produção de notas indicativas de significação (NIS) sobre cada TNS, objetivando apreender os seus significados e as suas relações no contexto global do corpus empírico;

c) Sistematização de eixos narrativos de significação (ENARS) para apreensão das relações gerais, particulares e singulares das significações produzidas pelos professores em suas narrativas;

d) Organização de unidades analíticas (UNA) e apreensão das categorias de análise (CALIS) para mediação da síntese analítica.

Feito isso, desenvolvemos a síntese analítica, pela qual explicamos as relações existentes entre os momentos do fenômeno apreendidos na análise. Acerca disso, Lefebvre (1991) considera que a síntese:

[...] situa o 'momento' no todo, no movimento, em seu posto, no conjunto das relações. Ela 'nega' esta negação, o momento isolado; na exata medida em que ele é isolado pelo entendimento e convertido em erro, a síntese o restabelece em sua verdade (LEFEBVRE, 1991, p. 120).

Nessa compreensão, o processo de análise que realizamos foi inseparável de sua síntese. Nos tópicos seguintes apresentamos a discussão que revela a síntese analítica de parte da investigação que originou este texto.

\section{A materialidade da docência no ensino superior}

Consideramos que a docência no ensino superior é atividade docente, e portanto, uma prática educativa. Assim, como todas as outras formas de prática educativa, a docência no ensino superior objetiva a formação humana pela mediação da cultura produzida no movimento sócio-histórico da sociedade. No movimento desenvolvido neste tópico, discutimos sobre a materialidade da docência no ensino superior, a fim de produzir compreensões sobre as particularidades desta prática educativa.

Ao considerarmos a docência no ensino superior como atividade docente, assim como um tipo particular de prática educativa, entendemos que ela está intrinsecamente ligada ao processo sócio-histórico de constituição desse nível de ensino. Esse processo tem suas 
determinações fundamentais baseadas na relação sociedade, educação e prática educativa. Para Pimenta e Anastasiou (2014, p.178), “[...] a profissão docente é uma prática educativa, ou seja: como outras, é uma forma de intervir na realidade social; no caso, mediante a educação. Ela é uma prática social".

Com base nessa afirmação, apreendemos que a atividade docente do professor do ensino superior direciona-se para "[...] o contexto da prática pedagógica; a ambiência da aprendizagem; o contexto sócio-histórico dos alunos, o planejamento das atividades de ensino; a condução da aula nas suas múltiplas possibilidades; e a avaliação da aprendizagem" (BROILO; FORSTER; FAGUNDES, 2009, p. 239).

A atividade docente do professor do ensino superior se articula às tradicionais atribuições da própria universidade, pautadas no ensino, pesquisa e extensão ${ }^{4}$. Pelo ensino, os alunos se apropriam dos conhecimentos produzidos ao longo da história pela humanidade; por meio da pesquisa, produzem-se novos conhecimentos que emergem sobre as necessidades da realidade; e através da extensão, intervém-se nas práticas sociais, identificando problemas, propondo soluções e realizando projetos que contribuam com o desenvolvimento da sociedade.

Essa tríade foi expressa na reforma universitária de 1968, durante o governo militar, e na Constituição de 1988, em seu artigo 207, e então passou a ser considerada o necessário indissociável aos objetivos da universidade contemporânea. Entretanto, a gênese dessa proposta está vinculada aos ideais humboldtianos ${ }^{5}$ e aos princípios neoliberais de construção da universidade. Esses princípios defendem a universidade com padrão de qualidade avançada, proposto pela lógica da economia de mercado, o que se tornou um desafio à universidade em virtude das condições estruturais e políticas do ensino superior.

Com o advento da Lei de Diretrizes e Bases da Educação Brasileira (LDB), n 9394/96, em seu artigo 45, fica regulamentado que a "[...] educação superior será ministrada em instituições de ensino superior, públicas e privadas, com variados graus de abrangências ou especialização" (BRASIL, 1996). O desenvolvimento da tríade ensino, pesquisa e extensão foi comprometido, sobretudo, porque abriu-se precedente para a promulgação do Decreto $\mathrm{n}^{\circ}$ 2306/97, que criou novas tipologias para instituições de ensino superior (IES), inclusive os centros universitários, faculdades integradas, institutos ou escolas superiores. Essas IES, ao contrário das universidades, não têm obrigatoriedade de oferecer o ensino, a pesquisa e a extensão de forma indissociável.

Como consequência, desenvolveu-se um processo de hierarquização do ensino, pesquisa e extensão, o que colocou, na maioria dos casos, a pesquisa como soberana nas Instituições de Ensino Superior (IES) em detrimento das demais atividades. Outro aspecto considerado como consequência dessa legislação é o aumento e diversificação das IES e a fragilização da docência no ensino superior. Almeida (2012) informa que, de acordo com a diversidade de perfis

\footnotetext{
${ }^{4}$ Em Morosini (2001, p. 22): “A instituição Universidade significa desenvolver ensino, pesquisa e extensão, ter autonomia didática, administrativa e financeira e congregar corpo docente com titulação acadêmica significativa de mestrado e doutorado".

5 Esses ideais fazem referência à "[...] gênese da universidade iluminista, concretamente realizada a partir do alvorecer do século XIX, particularmente em Wilhelm Von Humboldt (1767-1835), entre outros, porque inaugura ele na Universidade de Berlim tal projeto. Iluminista porque é sob esse ideário, manifesto desde os meados do século XVIII, que a consolidada universidade medieval se refaz em busca de identidade em vista dos novos tempos, agora urbanos, industriais e tecnológicos" (ARAÚJO, 2018, p. 26, grifos do autor).
} 
institucionais e seus objetivos variados, multiplicaram-se as exigências aos professores ${ }^{6}$. Em conformidade com isso, Pimenta e Anastasiou (2014, p. 8) reforçam que:

A universidade é uma instituição educativa cuja finalidade é o permanente exercício da crítica, que se sustenta na pesquisa, no ensino e na extensão, ou seja, a produção do conhecimento a partir da problematização dos conhecimentos historicamente produzidos e de seus resultados na construção da sociedade humana e dos novos desafios e demandas que esta coloca. Esses desafios são produzidos e identificados inclusive nas análises que se realizam no processo de ensinar, na experimentação e na análise dos projetos de extensão, por meio das relações que são estabelecidas entre os sujeitos e os objetos de conhecimento.

Disso, identificamos em Almeida (2012, p. 69) que a docência no ensino superior “[ [...] caracteriza-se por ser um conjunto de ações que pressupõe elementos de várias naturezas, o que impõe aos sujeitos por ela responsáveis um rol de demandas, contribuindo para configurá-la como um campo complexo de ação". Nessa articulação, a atividade docente desenvolvida pelo professor do ensino superior compreende ampla gama de responsabilidades e a significativa participação social desses profissionais na formação humana.

Para Franco (2012, p. 114), o professor do ensino superior atua em diversos tipos de instituições, e explica que:

\begin{abstract}
Desenvolve nelas atividades que se qualificam em diferentes formas, enfrenta tensões das mais variadas, seja com os pares da mesma ou de diferentes áreas, é um profissional não necessariamente somente da universidade, e mostra diferentes relações com o conhecimento, seja para produzi-lo ou disseminá-lo. Caracteriza-se pela diversidade, pela pluralidade de opções, caminhos, alternativas, interesses e tensões.
\end{abstract}

Desse modo, sendo colaborador no processo de transformação social dos indivíduos por meio da atividade docente, o professor do ensino superior tem participação social importante porque:

[...] como um profissional que realiza um serviço à sociedade, o professor universitário atua de forma reflexiva, crítica e competente no âmbito de sua disciplina, explicitando seu sentido, seu significado e sua contribuição no percurso formativo dos estudantes, inserida no projeto político-pedagógico dos cursos, vivenciado no cotidiano do ensino e da pesquisa (PIMENTA; ANASTASIOU, 2014, p. 10).

O contexto social, caracterizado pelas múltiplas transformações do mundo globalizado, altera padrões de valores e formas de organizar e produzir o conhecimento. Como consequência disso, emerge a necessidade de reconfiguração da universidade na contemporaneidade, para que se adapte à sociedade em constante mudança, imprimindo exigências à atividade do professor do ensino superior. Dentre essas exigências, destacam-se requisitos necessários ao exercício da docência. Para Pimenta e Anastasiou (2014, p. 38), esses requisitos dizem respeito

\footnotetext{
${ }^{6}$ Morosini (2001, p. 14) afirma que "[...] conforme o tipo de instituição de ensino superior em que o professor atua, sua docência sofrerá diferentes pressões. Se ele atua num grupo de pesquisa em uma universidade, provavelmente sua visão de docência terá um forte condicionante de investigação. Já se ele atua numa instituição isolada, num centro universitário, ou mesmo numa federação, sua visão de docência terá um forte condicionante de ensino sem pesquisa, ou, quando muito, do ensino com a pesquisa. A cultura da instituição e daí decorrente a política que ela desenvolve terão seus reflexos na docência universitária. Entretanto, é importante ressaltar que, mesmo nas instituições universitárias, a afirmação de que todos os docentes tenham a sua atividade relacionada à pesquisa não é verdadeira. As instituições têm diferentes graus de desenvolvimento de pesquisa em seu interior e mesmo entre as instituições".
} 
ao domínio de questões do campo educacional até então ausentes da docência no ensino superior, dentre elas:

[...] a qualidade da educação, a educação a distância e as novas tecnologias; a gestão e o controle do ensino superior; o financiamento do ensino e da pesquisa; o mercado de trabalho e a sociedade; a autonomia e as responsabilidades dos professores do ensino superior; as condições de trabalho, dentre outras. (...) uma vez que se espera envolvimento desses professores na administração e gestão de seus departamentos, na universidade, tomando decisões sobre currículos, políticas de pesquisa, de financiamento, não apenas em seu âmbito, mas também no âmbito dos sistemas públicos estaduais, do sistema nacional de educação e das instituições científicas de fomento, de políticas de pesquisa, ensino e avaliação.

Ainda sobre essas questões, Fávero e Tauchen (2013, p. 236) consideram que o professor do ensino superior e sua atividade docente encontram-se em permanente conflito, visto que "[...] a docência, como atividade profissional, tornou-se mais complexa com as transformações culturais e com o surgimento de novas condições e exigências de trabalho: massificação da escolarização, novas tecnologias, programas institucionais, entre outros".

Essas transformações e exigências típicas da atividade docente refletem no desenvolvimento das dimensões pessoais, profissionais e institucionais do professor do ensino superior. Em síntese, as três dimensões, articuladas entre si, traduzem uma possibilidade de formação docente numa perspectiva de desenvolvimento profissional, pois a formação de professores "[...] pressupõe a organização de um processo contínuo e sistemático que considere as exigências sociais, psicológicas, pessoais, contextuais e profissionais como parte do desenvolvimento profissional docente" (BOLZAN; ISAIA; MACIEL; 2013, p. 52). Essas dimensões, portanto, representam as diversas relações que o professor desenvolve no âmbito da sua atividade docente.

A dimensão pessoal envolve as motivações, as vivências dos professores, o envolvimento e compromisso com a docência, bem como a busca pelo desenvolvimento. Para Isaia (2003, p. 249) a dimensão pessoal se desenvolve por meio de um duplo movimento ${ }^{7}$ mediado pelas significações do professor, explicitado quando compara:

As vivências afetivas brotam da dimensão pessoal e se expandem para a profissional, voltando a incidir novamente sobre a primeira, em um movimento recorrente e espiralado. Assim, o pessoal e o profissional se alimentam mutuamente, repercutindo na riqueza/diferenciação emocional que os professores podem vivenciar.

A dimensão pessoal compreende uma unidade constituída pela pessoa e pelo profissional, em que se determinam a própria ideia de docência e o ser professor. Compreendemos com isso que, na dimensão pessoal, se desenvolvem os processos de reflexão sobre os sentidos e os significados da docência no ensino superior, bem como as necessidades do professor em relação à sua constituição profissional; isto é, suas singularidades, particularidades e generalidades no tocante à docência.

A dimensão profissional integra as ações que o professor realiza para satisfação das suas necessidades profissionais, e a principal delas são os processos formativos. Morosini (2006, p. 376) ajuda a entender que a dimensão profissional abrange o processo de "[...] apropriação de um repertório de conhecimentos, saberes e fazeres voltados para o exercício da docência". Já Batista e Meireles (1984, p. 14) nos alertam que essa dimensão da atividade docente

\footnotetext{
7 Morosini (2006, p. 376), ao fazer referência a esse duplo movimento, destaca que este ocorre quando os professores, ao mesmo tempo que “(...) se reconhecem como sujeitos dessas atividades, são capazes de se distanciarem e fazer com que elas se tornem objeto de suas reflexões".
}

\# Tear: Revista de Educação Ciência e Tecnologia, v.10, n.2, 2021. 


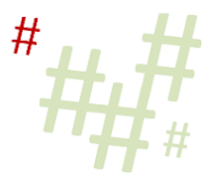

corresponde a "[...] um determinado estágio ou setor da vida das pessoas, fixando-se na posição e papel que o indivíduo desempenha como parte de um grupo profissional e nas suas perspectivas de crescimento e carreira".

A terceira dimensão, a institucional, compreende as relações estabelecidas pelos professores em seu ambiente de trabalho, assim como as condições de trabalho, e suas contribuições para a melhoria e qualidade da atividade docente desenvolvida na instituição. Para isso, Batista e Meireles (1984, p.14) explicam que essa dimensão "[...] diz respeito às funções que o indivíduo desempenha em determinada organização, detendo-se na análise das possibilidades que esta lhe oferece para o próprio desenvolvimento e aperfeiçoamento no desempenho do seu papel organizacional".

O modo como cada professor articula as três dimensões, ao longo do seu processo constitutivo, compreende sua atividade docente. E, nesse movimento, seu processo transformativo se expressa nessas dimensões. É por meio das relações desenvolvidas nessas dimensões que surgem novas necessidades para o professor, o que é condição determinante para o aparecimento de contradições decisivas em seu desenvolvimento profissional. Nesse sentido é que Isaia e Bolzan (2008, p. 46) reforçam a necessidade de investigações que "[...] levem em conta a trajetória vivencial dos professores e o modo como eles articulam o pessoal, o profissional e o institucional e, consequentemente, como vão se (trans)formando, no decorrer do tempo".

Para Almeida (2012), o desenvolvimento de propostas formativas que identifiquem a docência no ensino superior como prática educativa, complexa e transformadora, pautada na articulação das dimensões pessoais, profissionais e institucionais dos professores do ensino superior, devem considerar alguns requisitos básicos:

\begin{abstract}
a) concepções a respeito de si próprio e do papel social que dão sustentação à identidade profissional; b) componentes que integram os processos formativos, como teorias e práticas, conteúdos da área específica de atuação, conhecimentos didáticopedagógicos; c) contextos de formação e de trabalho; d) processos de construção do conhecimento e de desenvolvimento profissional (ALMEIDA, 2012. p. 73).
\end{abstract}

Essas questões reforçam o grande desafio em relação aos processos formativos para a docência no ensino superior. Isso envolve compreender como se forma e se transforma o professor do ensino superior, e se essa formação possibilita as condições necessárias ao desenvolvimento de sua atividade docente articulada ao ensino, pesquisa e extensão.

Ao trazer argumentos que evidenciem bases teórico-metodológicas para os processos formativos do professor do ensino superior, Almeida (2012) propõe três princípios norteadores da formação: 1) articulação teoria e prática; 2) importância da integração entre a dimensão disciplinar e pedagógica dos conteúdos; 3 ) A formação como um continuum que ganha vida ao longo de suas etapas em direção ao desenvolvimento profissional.

Consideramos que, ao propor a dialética da relação teoria e prática como primeiro princípio norteador dos processos formativos do professor do ensino superior, Almeida (2012) pretende reforçar a relevância dos conhecimentos necessários à docência, articulados ao desenvolvimento da atividade desse professor. Esse pensamento alinha-se à compreensão de que a "[...] mediação da prática coloca-se como indispensável; porém, em estreita articulação com a teoria e ancorada na reflexão, como processo que busca atribuir sentido àquilo que se pratica" (PIMENTA; ANASTASIOU, 2014, p. 13). Isso porque, no desenvolvimento de sua atividade, todo professor necessita não somente da prática, mas também da sua compreensão em níveis complexos. 
Nessa relação, é importante compreender a relativa autonomia da teoria em relação à prática educativa do professor do ensino superior. Uma vez que ao "[...] manterem uma e outra relações de unidade e não de identidade, a teoria pode dispor de certa autonomia em relação às necessidades práticas" (VÁZQUEZ, 1980, p. 44). Essa afirmação deve ser interpretada cuidadosamente, pois conforme destaca o autor, trata-se de uma autonomia relativa, tendo em vista que cabe à prática o papel determinante como fundamento, critério de verdade e fim da teoria.

Disso, consideramos que os conhecimentos pedagógicos como elementos essenciais à prática educativa do professor de ensino superior, possibilitam-lhe antecipação à realização da referida prática. Pois, com base nos conhecimentos da prática, é possível abstraí-la da realidade, transformá-la em concreto, pensado diante da situação futura. Para Vázquez (1980, p. 44), ao produzir "[...] esse modelo ideal, a teoria evidencia a sua autonomia relativa, já que sem esperar que se opere um desenvolvimento real, efectivo, pode propiciar uma prática inexistente ao antecipar-se-lhe idealmente".

O segundo princípio norteador da formação do professor de ensino superior tem certa articulação com o primeiro. Ele se refere à necessidade de aprendizado de conhecimentos científicos do campo de estudos do professor, para além da pesquisa científica, que produzam relações com as compreensões pedagógicas e didáticas de sua atividade docente. Dessa maneira, esse princípio objetiva a estruturação do pensamento pedagógico docente e representa grande desafio nos processos de formação docente.

Pautados na ideia de que para o desenvolvimento da atividade docente os conhecimentos específicos da disciplina já são suficientes, muitos professores ignoram os conteúdos pedagógicos necessários à sua formação. E quando esses docentes estão no ensino superior, o problema se torna ainda mais grave, pois ao atuarem como formadores de outros professores, passam a socializar uma cultura que reduz a função social do professor ao ensino e à reprodução de conteúdos específicos.

Essa relação entre os conhecimentos específicos e pedagógicos é essencial para que o professor do ensino superior aprofunde sua relação com a docência, no sentido de produzir reflexões sobre suas necessidades formativas, devendo relacionar teoria e prática em sua atividade docente. Nesse sentido, Libâneo $(2015$, p. 12) afirma que o professor “[...] deve não só dominar o conteúdo, mas, especialmente, os métodos e procedimentos investigativos da ciência ensinada. Portanto, o conhecimento disciplinar e o conhecimento pedagógico estão mutuamente integrados".

Essa necessidade do professor de relacionar conhecimento com a atividade docente remete ao terceiro princípio apresentado por Almeida (2012), visto que pretende articular a ideia de formação docente a um processo permanente de desenvolvimento profissional. Esse princípio articula-se ao princípio anterior como outro grande desafio aos processos formativos do professor do ensino superior. Sobre essa articulação, Torres $(2014$, p. 9) considera que as relações entre a formação e o desenvolvimento profissional docente ainda não são uma realidade concreta nos programas e espaços formativos investigados. Isso ocorre porque as instituições têm seus programas centrados nas necessidades institucionais e pouco contemplam as fases da carreira docente. Mesmo assim, a autora propõe que:

[...] a formação do professor tem uma relação dialética com seu desenvolvimento profissional. Por isso, a formação acontece em relação à prática educativa da Educação Superior, considerando seu contexto e as vivências dos professores como espaço de construção de aprendizagens, ou seja, uma concepção de formação na qual 
a instituição possa se questionar sobre quais as oportunidades de aprendizagens que ela oferece como também as influências que sofre e exerce reciprocamente o professor. São, portanto, aprendizagens situadas por estarem na relação diretamente contextual e por serem incorporadas e construídas na relação do docente com a situação concreta de trabalho, tendo a ver com a experiência desse sujeito. Logo, a aprendizagem aqui discutida tem fonte social e se integra ao trabalho docente como sendo pessoal e profissional, tendo nas experiências da sala de aula e na instituição seus componentes estruturadores (TORRES, 2014, p. 128).

Essas questões levantadas pela autora apresentam-se como dados que confirmam a docência no ensino superior, fragilizada por conta da diversidade de IES e, das hierarquias entre ensino, pesquisa e extensão. Também há de se considerar a dinamicidade da sociedade contemporânea e as políticas omissas em relação à formação do professor do ensino superior. Torres (2014) compreende que as propostas que trabalham com a formação docente articulada ao desenvolvimento profissional são fundamentais. Tais propostas devem estender-se para a formação pedagógica, visando à ampliação das dimensões pessoais, profissionais e institucionais dos professores.

As discussões teóricas engendradas nesses primeiros tópicos mediaram nossas compreensões sobre questões fundamentais relacionadas ao ensino superior, de modo que nos orientaram no processo de produção e análise de dados e nas reflexões originadas a partir das narrativas dos professores sobre suas motivações para a docência no ensino superior. No tópico seguinte apresentamos uma síntese de nossas análises sobre essas motivações.

\section{As motivações do professor para a docência no ensino superior}

O objetivo deste tópico é apresentar parte da síntese analítica originária da tese que resultou neste artigo. Nele, discutimos a gênese dos professores colaboradores da investigação (PCIs) na docência e na docência do ensino superior. Nesse movimento, constatamos que, antes de ingressarem no ensino superior, todos eles atuaram na educação básica, o que orientou diversas necessidades e motivações dos PCIs ao longo do seu processo constitutivo, inclusive, no desenvolvimento da atividade docente no ensino superior.

O ingresso desses professores na docência foi mediado por vivências que se originaram das suas relações afetivas no contexto familiar e social. Nesse início, a dimensão pessoal dos PCIs foi o que definiu essa escolha. Na dimensão pessoal, os sentidos e os significados de docência se confundiam em um só. Somente com o ingresso na docência e a inter-relação entre as dimensões pessoais e profissionais, é que essas significações se transformaram. Para Isaia e Bolzan (2008, p. 49), a mediação da dimensão pessoal na escolha pela docência:

[...] indica um forte componente de envolvimento afetivo com a docência desde um período prévio. Um fator preponderante nesta escolha encontra-se em uma inclinação afetiva que denominamos, a partir de resultados de nossas pesquisas, de sentimentos docentes. Eles podem constituir-se na escolha profissional e, principalmente, ao longo da docência, em elementos dinamizadores da atividade educativa dos professores.

$\mathrm{Na}$ ótica das autoras, os 'sentimentos docentes' afetam as primeiras significações dos professores sobre a docência e suas ações para o desenvolvimento da profissão. Em Huberman (2013), o ingresso na docência representa um momento de 'descoberta' e 'sobrevivência', sendo esse momento o início da constituição do ser professor. Em suas palavras,

O aspecto da 'sobrevivência' traduz o que se chama vulgarmente de 'choque do real', a confrontação inicial com a complexidade da situação profissional: o tatear constante, a preocupação consigo próprio ("Estou-me a aguentar?"), a distância entre os ideais e 
as realidades quotidianas da sala de aula, a fragmentação do trabalho, a dificuldade em fazer face, simultaneamente, à relação pedagógica e à transmissão de conhecimentos, oscilação entre as relações demasiado íntimas e demasiado distante, dificuldades com os alunos que criam problema, com material didático inadequado, etc. Em contrapartida, o aspecto da 'descoberta' traduz o entusiasmo inicial, a experimentação, a exaltação por estar, finalmente, em situação de responsabilidade (ter a sua sala de aula, os seus alunos, o seu programa), por se sentir colega num determinado corpo profissional (HUBERMAN, 2013, p. 39).

Compreendemos, assim, que somente após a formação inicial e o ingresso na docência, os professores de fato vivenciaram a realidade educacional. Essa vivência mediou as novas significações acerca dos sentidos e os significados de docência, as necessidades em relação, e, consequentemente, o estágio inicial do processo de desenvolvimento profissional ${ }^{8}$.

Nas significações de Calíope, ficou evidenciado que sua motivação pela docência foi orientada pela referência familiar. Sua mãe era professora alfabetizadora, e essa referência não só mediou a escolha pela profissão, como também os interesses de Calíope sobre os estudos de alfabetização e letramento. Em suas narrativas, a professora destacou:

\begin{abstract}
Minha referência para ingressar na docência foi familiar. Minha mãe era professora alfabetizadora, eu sempre gostei de brincar de ser professora, ela foi minha referência, pela escolha profissional. Então não pensei duas vezes. Me formei professora no Magistério, fiz Magistério, depois eu fiz Pedagogia, e sempre trabalhando na educação básica. E, somente em 2005, por aí, foi que me veio essa questão de ser professora da universidade, como a gente sempre falava, professora do ensino superior, né? Até então estava muito focada mesmo com essa questão de ser professora na educação básica, sou professora alfabetizadora, então eu sempre trabalhei mais com esse público, de crianças, professora de crianças. Então, eu sou professora iniciante, posso me considerar assim, no ensino superior, mas já tenho uma experiência... uma experiência maior na educação básica, como professora da educação básica, que foi exatamente, assim, a motivação, vamos dizer assim, para essa construção da questão da docência (CALÍOPE).
\end{abstract}

Naquele momento, o sentido da docência para Calíope estava relacionado à sua identificação com a profissão da mãe e às afetações produzidas pelas brincadeiras da infância. Foi paixão! Entretanto, outras vivências, envolvendo a relação profissional com a área de alfabetização e letramento, orientaram o movimento da professora na sua constituição docente. O sentido da educação para Calíope foi transformado. Seu envolvimento com a educação básica, com a formação de professores alfabetizadores e com a educação infantil foram determinantes para essa transformação.

Em movimento semelhante, Morpheu também afirmou que sua relação familiar foi fundamental na escolha pela docência. A vivência numa família em que as irmãs e a mãe eram professoras mediou a primeira necessidade, que originou a relação dialética envolvendo a realidade do jovem Morpheu com as possibilidades de ser professor:

Primeiro eu preciso falar da minha própria escolha pela carreira docente. Eu tenho uma família... eu tenho uma tradição familiar no magistério, né? Tenho duas irmãs que são professoras, minha mãe foi professora. Então, o magistério é uma marca familiar. E isso eu sempre acompanhei a vida docente, vida profissional dos meus familiares da docência. Como eu sou filho temporão, muito próximo da mãe, muito

\footnotetext{
${ }^{8}$ Para Garcia (2010, p. 30): “Os primeiros anos de docência não só representam um momento de aprendizagem do 'ofício' do ensino, especialmente em contato com os alunos nas classes. Significam também um momento de socialização profissional”.
} 
próximo dos irmãos, das irmãs, sempre foi muito familiar, escutar as histórias da época que minha mãe foi professora, vivenciar as experiências das minhas irmãs professoras. Tudo isso foi... era muito prazeroso para mim. Eu, criança, eu vivenciava tudo isso de forma muito prazerosa. Nas brincadeiras de criança eu sempre exercia a função de professor. Então não foi difícil fazer essa escolha, né? Eu carrego... eu tenho essa marca familiar e isso foi que influenciou, influenciou de forma imensa mesmo a minha escolha pela profissão docente (MORPHEU).

Do que analisamos, Morpheu desenvolveu relação afetiva com a docência antes mesmo de ser professor. Ao utilizar a expressão "Não foi difícil fazer essa escolha, né?", ele se assemelhou a Calíope, quando ela se expressou sobre a escolha pela docência: "Eu não pensei duas vezes!". O que compreendemos é que a vivência familiar, isto é, as relações no contexto familiar, foram determinantes nas motivações desses professores para ingressarem na docência:

\begin{abstract}
A gente não se torna professor de uma hora para outra, né? A gente não... não vai dormir e acorda dizendo 'eu vou ser professor'. Então eu falei que o meu 'ser professor' ou a minha escolha pela profissão teve uma influência muito grande da minha família, né? Minha família que tem uma tradição no magistério. Então desde quando eu era criança, que eu escutava as histórias da minha mãe e tudo, isso tudo foi interferindo e conviver com esse mundo educacional dentro da minha casa, com esse mundo da docência dentro da minha casa foi me deixando curioso, eu me lembro que eu era criança e eu tinha o sonho de ter uma escola. Uma vez eu fiz um bilhete para minha irmã dizendo que... eu me lembro que eu deixei um bilhete para ela que eu ia montar uma escola, que eu ia ser dono de uma escola, né, que eu ia criar uma escola e eu era criança, né? (MORPHEU).
\end{abstract}

Para Orpheu, sua escolha pela docência também foi mediada por uma vivência. No caso desse professor, a relação afetiva com a docência se originou nos tempos de juventude, quando desenvolveu ações com a educação popular. O ingresso na Pastoral da Juventude, e com ele, a vivência com a educação popular, foram determinantes para as motivações desse professor. Diferentemente dos demais PCIs, as motivações de Orpheu se relacionavam com a prática educativa que ele já desenvolvia na Pastoral da Juventude. Nas palavras do professor:

O que me motivou a ser professor foi minha inserção nas pastorais sociais. Desde a adolescência, eu fui da Pastoral da Juventude, e esse trabalho com a educação popular foi bastante inspirador para minha escolha enquanto profissão. Porque, de fato, no trabalho da Pastoral da Juventude, desde os grupos de jovens, até mesmo no trabalho da coordenação da Pastoral da Juventude, a gente exercia aquele papel de educador popular, de formador. Então, isso foi me inspirando, era um trabalho que a gente já estava fazendo, de certo modo, que quando eu fui para o ensino médio, para a universidade, de fato, a minha escolha era para ser professor. Porque era um trabalho que a gente já tinha familiaridade, que a gente já tinha uma vivência com esse trabalho de educação do outro, de formação do outro. Então, isso foi bastante decisivo na escolha da minha profissão. Eu ingressei na educação básica em 1988, via concurso público. Atuei primeiramente nas creches como coordenador pedagógico. Lá eu fui coordenador, secretário, gestor e nesse processo eu fiquei praticamente 2 anos. Eu também articulei com a universidade, um projeto para formação dos professores da creche. Esse trabalho me deu visibilidade e na sequência, fui convidado pela Secretaria de educação para assumir a função de coordenador pedagógico, o qual fiquei três anos fazendo assessoria junto às escolas. Somente com a mudança de gestão, é que irei para a sala de aula, atuar no ensino fundamental em turmas de quinta e sexta séries com a disciplina Ética e, depois, com Filosofia. Depois de três anos eu retornei para a Secretaria de Educação trabalhar como formador de professores da educação básica (ORPHEU).

Conforme apreendemos, a inserção de Orpheu na docência teve como motivações suas relações com os movimentos sociais, fator determinante para a compreensão de uma das 
particularidades que identificamos no processo constitutivo desse professor: a militância ${ }^{9}$ na educação. Consideramos que essa particularidade, originada antes da docência, esteve presente ao longo de todo o processo constitutivo de Orpheu.

A particularidade do professor também contribuiu para seu envolvimento com as questões da formação dos professores da educação básica de seu município, o que foi representado pelas funções de gestão e coordenação, assumidas nas escolas onde atuou e na Secretaria Municipal de Educação.

$\mathrm{O}$ aspecto que particularizou a escolha desses PCIs em relação à docência foi determinado pela apreensão dos sentidos e significados de docência nas relações sociais que desenvolveram com outros indivíduos. Como vimos no primeiro momento, essas significações foram mediadas por vivências que não evidenciavam a docência e a realidade educacional na sua generalidade. Num segundo momento, após a formação inicial, o ingresso na docência e a vivência da realidade educacional, essas significações se transformaram e mediaram as novas necessidades desses professores em relação à sua profissão. Para Guarnieri (2005, p. 9), "uma parte da aprendizagem da profissão docente só ocorre e só se inicia em exercício. [...] $\mathrm{O}$ exercício profissional é condição para consolidar o processo de tornar-se professor". Nesse contexto, se estabeleceram as dimensões pessoais, profissionais e institucionais dos professores, as quais são explicadas por Isaia e Bolzan (2008, p. 47), quando esclarecem que a profissão

[...] é influenciada, tanto pelas características pessoais (trajetória de vida) dos professores, quanto pelas profissionais (contexto institucional em que estão inseridos). Nesse sentido, é importante considerarmos, de modo integrado, as alterações vivenciais e as maneiras como os professores encaram a docência.

O entendimento de que a profissão é mediada pelas dimensões pessoal e profissional reforça a ideia de que é a realidade social que medeia a formação do ser humano. Vigotski (2018, p. 90) nos faz compreender essa ideia quando explica que "[...] o homem é um ser social e, fora da relação com a sociedade, jamais desenvolveria as qualidades, as características que são resultado do desenvolvimento metódico de toda a humanidade". Do mesmo modo, essas relações sociais com seu mundo pessoal, profissional e institucional foram determinantes para o ingresso desses professores no ensino superior.

Com base nas narrativas desses professores, o ingresso na docência do ensino superior se deu de modo distinto. No entanto, um aspecto que particularizou a relação deles com a docência no ensino superior foi a mediação do que vivenciaram na educação básica no desenvolvimento da atividade docente, realizada no ensino superior. Para esses professores, a atividade desenvolvida no ensino superior tinha função determinante na qualidade da educação básica. Isso ocorre porque eles se identificavam como professores formadores de professores da educação básica.

Em sua primeira relação com o ensino superior, por exemplo, Calíope atuou como coordenadora de pós-graduação em faculdade privada. Entretanto, essa vivência despertou-lhe o interesse pela docência nesse nível de ensino:

Tive algumas experiências não tão longas em relação à questão do ensino superior, já nesse primeiro contato, a princípio não como professora, mas como coordenadora de

\footnotetext{
${ }^{9}$ Para Formosinho e Ferreira (2009, p. 29), na concepção de professor militante, “[...] o professor vê-se como um agente social comprometido com a escola e com a comunidade local. Ele reconhece que há professores mais dinâmicos e empenhados, mas a avaliação deste dinamismo e empenhamento só pode ser feita pelos pares e pela comunidade. Esta é que é considerada a verdadeira avaliação, pois exprime o prestígio e a capacidade do professor, mas não deve ter efeitos formais na carreira".
} 

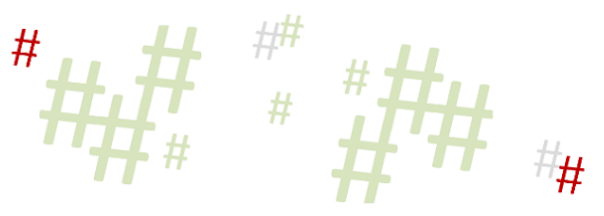

Pós-graduação no âmbito da especialização numa faculdade particular, e eu comecei também a me motivar cada vez mais por esse espaço novo do ensino superior (CALÍOPE).

Ao ingressar no ensino superior como docente, a vivência de Calíope com a educação básica mediou momentos de reflexão entre o 'ser professora' da educação básica e o 'ser professora' do ensino superior. Nesse diálogo interno, a experiência na educação básica mediou o desenvolvimento da sua atividade docente no ensino superior:

Eu acho que ser professora da educação básica me ajudou muito nessa constituição da
identidade de ser professora da educação superior, por quê? Porque eu vim trabalhar
num curso de formação de professores, né? Então nesse movimento eu, de certo modo,
ao tempo em que eu ministrava as disciplinas aqui no ensino superior, eu também
pude fazer uma análise, uma reflexão sobre a minha prática na condição de professora
da educação básica, embora eu não estando mais, eu não estivesse mais ali atuando
com as crianças, né? Porque eu já estava na Secretaria de Educação ocupando esses
espaços de coordenação pedagógica. Mas eu fazia esse movimento nas aulas, por
exemplo, os exemplos que eu dava, eu dava a partir da minha prática, então isso me
ajudou muito (CALÍOPE).

Para a professora, a vivência na educação básica foi considerada fundamental para o desenvolvimento de sua atividade docente no ensino superior. Conforme a docente, o fato de atuar em um curso de formação de professores, em que lecionaria para discentes que iriam atuar em um nível de ensino que ela já havia vivenciado como professora, era percebido como oportunidade de socialização dessas práticas com seus alunos. Esse movimento que envolveu a concreticidade da sua atividade docente na educação básica, com o desenvolvimento das disciplinas que ministrava no ensino superior, também representou articulação da teoria com a prática.

Em se tratando do ingresso de Morpheu no ensino superior, ocorreu quase que paralelo ao seu ingresso na educação básica. Para esse professor, a motivação para o exercício da docência no ensino superior estava relacionada ao desejo de tornar-se pesquisador e contribuir com a produção do conhecimento científico em educação. Conforme o que foi apresentado, o ensino superior reunia as condições determinantes para essa realização. No entanto, as relações desse professor com a docência na educação básica continuavam fortes:

Meu ingresso no ensino se deu logo após que eu concluí a graduação. Eu dava aula
no curso de Psicologia e Pedagogia. Inicialmente, por convite, e logo em seguida, já
passei para o seletivo de professor substituto da universidade. A motivação que eu
tive para buscar esse novo campo de atuação foi que eu sempre sonhei em ser
professor do ensino superior. Eu me lembro de quando eu era estudante no início do
curso de graduação e eu dizia: Eu vou voltar para cá como professor, para
universidade como professor! Eu dizia sempre isso e eu tinha esse sonho! E esse meu
ingresso no ensino superior, não provocou meu afastamento da educação básica.
Então a motivação que eu tive foi essa, eu também desejava me transformar em um
pesquisador. Eu desejava me aprofundar mais nos estudos, nas leituras, nas teorias.
Eu desejava produzir mais teorias. Isso tudo, embora hoje eu saiba que isso é possível
na educação básica. Eu entendia na época, e continuo entendendo hoje que no ensino
superior isso é mais acessível. Então esse desejo de me tornar pesquisador, foi o que
me motivou a ingressar no ensino superior (MORPHEU).

O conhecimento e a vivência da realidade da educação básica também foram significados por Morpheu como mediadores da sua atividade no ensino superior. O professor compreende que essa relação de articular a teoria da formação inicial com a socialização da sua prática na educação básica oportunizou aos alunos a compreensão de situações concretas da realidade educacional: 
Atuando na educação básica, tanto na sala de aula como na coordenação de escola, eu fui coordenador de escola, fui supervisor de escola, trabalhei em secretarias da educação, tanto na Secretaria Estadual como na Secretaria Municipal de Educação. Fui secretário municipal de educação. Então, essa vivência... eu vivi muito tempo na educação básica, muito tempo. Mas, por outro lado, eu também iniciei muito cedo a docência do ensino superior, eu fazia isso de forma paralela, enquanto eu tinha a minha atividade, o meu trabalho na educação básica eu também já trabalhava na educação superior, já era professor do ensino superior. Então eu tinha esse trabalho de forma paralela e para mim era uma forma de integrar... sempre me deixou, fez com que eu fosse um professor de ensino superior, formador de professores com o pé no chão. Por quê? Porque eu... ao tempo em que eu estava em contato com os estudos, com as leituras do campo da formação, eu estava em contato também com o chão da escola, eu estava em contato também com as problemáticas, com os dilemas que os gestores escolares vivenciavam, que os professores das escolas vivenciavam. Então, isso favoreceu que eu fosse equilibrando, não só (o meu discurso), mas equilibrando as minhas práticas também enquanto formador de professores, enquanto docente de ensino superior e formador de professores (MORPHEU).

Em consonância com as significações de Morpheu e Calíope, Oliveira (2008, p. 2) reforça que o "[...] peso de analisar o ensinar e o aprender dentro de um contexto cultural não se restringe ao que se passa no ambiente de formação, mas está no relacionamento e no movimento do significado social do que é vivido dentro e fora desse espaço". Essa compreensão ficou mais clara quando os professores, ao utilizarem de suas vivências na educação básica como referência para o desenvolvimento de sua atividade docente no ensino superior, apresentaram aos alunos situações e exemplos reais que seriam vividos pelos futuros professores no exercício da profissão. Vejamos o relato de Morpheu:

Agora, qual é o grande lance de tudo isso? Preparar-nos ou preparar os nossos alunos
para enfrentar esses problemas, esse é o grande lance. Os meus alunos, pelo menos eu
tento fazer com que eles não tenham choque quando eles chegam nas escolas, eles
não... no que depender de mim eles não constroem uma visão errônea do que é a escola
ou ilusória do que é a escola, pelo contrário, eles constroem uma visão onde eles se
sentem atores, participantes mesmo, protagonistas de um processo em que eles podem
criar estratégias de enfrentamento para os problemas que poderão ser vivenciados
cotidianamente. Por quê? Porque eles já sabem que lá vai ser um lugar onde eles vão
precisar agir, lá vai ser um lugar onde eles vão precisar atuar com estratégias de
enfrentamento aos problemas, para superar esses problemas para poder alcançar os
objetivos institucionais da escola e os objetivos didáticos deles em particular
(MORPHEU).

Para Morpheu, era importante explicar aos alunos que a concreticidade da atividade docente não se constituía do sentido 'romântico' da educação, e que no exercício da profissão haveria desafios, incertezas, conquistas, necessidades, rupturas e continuidades. A tomada de consciência dos alunos acerca dessa realidade era compreendida pelo professor como de fundamental importância para o processo formativo. Essa significação de Morpheu vai ao encontro do que Gatti (2013) ressalta quando expressa que a preocupação dos professores em formar seus alunos para os desafios da contemporaneidade é entendida como exigência para o desenvolvimento da atividade docente. Em suas palavras:

A preocupação com a educação escolar, com a escola, nos reporta a pensar em pessoas, em relações pedagógicas intencionais, portanto, em profissionais bem formados para isso, dentro das novas configurações sociais e suas demandas; profissionais detentores de ideias e práticas educativas fecundas, ou seja, preparados para a ação docente com consciência, conhecimentos e instrumentos (GATTI, 2013, p. 54). 
É importante destacar que esse não era um pensamento singular de Morpheu. Os demais professores também significaram a função social do ensino superior na formação dos profissionais da educação básica e na dialética com os desafios da contemporaneidade.

Ademais, para Orpheu, sua motivação pela docência no ensino superior iniciou ainda no período da formação inicial. A orientação de ex-professores, a necessidade de poder retornar à instituição e colaborar com a formação de futuros professores foi significada como possibilidade para seu futuro profissional. Conforme Orpheu:

\begin{abstract}
Então, bom, o meu interesse pelo ensino superior ele está marcado por duas situações que eu considero bastante significativas. A primeira foi pelo fato de eu ter sido aluno dessa instituição. Então quando aluno dessa instituição eu sempre fui considerado aqui como o único das pessoas, um dos alunos questionadores. E nesse processo de formação enquanto acadêmico, aqui nesta instituição, eu fui me dando conta de que eu tinha possibilidade de um dia ingressar ao ensino superior porque eu tive bons professores que sempre, a partir de elogios, mas também que faziam considerações a respeito do meu desenvolvimento acadêmico e sempre me colocava essa possibilidade de um dia voltar para instituição e contribuir com os quadros de formação de outros futuros professores (ORPHEU).
\end{abstract}

Embora a motivação pela docência no ensino superior tenha afetado Orpheu durante a formação inicial, sua vivência na educação básica foi o que mediou sua relação com o ensino superior. A necessidade de contribuir com a qualidade da educação básica por meio da formação dos professores desse nível de ensino, em especial, os professores alfabetizadores, também foi fonte de motivação, que mediaram tanto a sua atividade docente no ensino superior, como o surgimento de novas necessidades formativas à sua constituição profissional:

\begin{abstract}
Mas o que de fato marcou mesmo a minha inserção no ensino superior, opção de vir para o ensino superior, foi exatamente a minha experiência na educação básica como professor formador. Sobretudo num período em que em 2000 a 2004, quando eu vivenciei uma experiência junto àqueles programas de formação de professores alfabetizadores, organizado pelo Ministério da Educação em parceria com as Secretarias de Educação. Mas assim, o que eu destaco dessa opção de vir para o ensino superior foi exatamente as lacunas de formação dos professores da educação básica que a gente tem observado já na qualidade tanto de formador, como também de pesquisador, e tem sido objeto hoje, inclusive, hoje, tanto das pesquisas que a gente desenvolve aqui na instituição, no sentido de compreender esse processo formativo dos professores, do seu desenvolvimento profissional na educação básica e fazer isso, de um certo modo, da melhor forma possível (ORPHEU).
\end{abstract}

Considerando a síntese analítica produzida neste tópico, evidenciamos, por meio das significações produzidas pelos PCIs sobre o ingresso na docência e na docência no ensino superior, a gênese das necessidades e motivos dos professores em relação à sua constituição profissional. A primeira de todas essas necessidades, certamente, foi a escolha pela profissão docente. Como vimos, dentre as motivações, destacamos as afetações familiares, o envolvimento com movimentos sociais, a intervenção de ex-professores, além da possibilidade de colaboração com o desenvolvimento da educação básica.

Diante do que explicamos até aqui, fica evidente que o processo de se tornar professor não se realizou de forma natural, mas o contrário: é um processo histórico-social, semelhante ao que Leontiev (1978, p. 285) explica quando afirma que:

[...] as aptidões e caracteres especificamente humanos não se transmitem de modo algum por hereditariedade biológica, mas adquirem-se no decurso da vida por um processo de apropriação da cultura criada pelas gerações precedentes. 
Compreendemos, assim, que tornar-se professor não foi resultado somente da relação afetiva ou do simples desejo de ser professor. Conforme Isaia e Bolzan (2009, p. 136), tornarse professor:

[...] exige um permanente processo de aprendizagem que acompanha toda a trajetória do professor, indicando toda sua incompletude como ser humano e como docente. A aprendizagem, seja qual for, faz parte da natureza humana. Cada um nasce na condição de aprendiz e o que faz com essa ferramenta humana depende de inúmeros fatores, tanto exógenos quanto endógenos. Aprender durante toda a vida e ao longo da trajetória docente é um fato ou circunstância que todo professor precisa aceitar, para poder construísse profissionalmente.

O processo constitutivo desses professores foi sócio-histórico, permeado de apropriações e objetivações em que estiveram envolvidas, além das necessidades e motivos, as ações e operações constitutivas da atividade humana. "O homem é um ser social e como tal está sempre ligado às condições sociais. [...] o indivíduo é sempre o ponto de partida" (SCHAFF, 1967, p. 55). Como ponto de partida, cada professor é sempre uma possibilidade. O seu desenvolvimento profissional se realiza no movimento das suas ações, da consciência de suas necessidades e da realidade profissional para constituir-se.

\section{Algumas considerações}

As discussões tecidas neste texto nos aproximam das compreensões sobre o que constitui a materialidade da prática educativa e os princípios norteadores dos processos formativos do professor do ensino superior. Na totalidade do movimento dialético que envolve a prática educativa e os processos formativos, constatamos a existência do movimento constitutivo do ser professor, isto é, do seu desenvolvimento profissional.

Enquanto forma particular de prática educativa, a docência no ensino superior estabelece a mediação do saber mais complexo da cultura à formação do ser humano, o que significa que a docência no ensino superior é uma prática social transformadora da sociedade. Essa constatação se dá pela sua contribuição na formação profissional e pessoal de cada indivíduo que tem, na universidade, a oportunidade de aprender e de se desenvolver, e também de ter acesso a uma formação que o incite a ser sujeito ativo na realidade social.

A materialidade da docência no ensino superior é orientada pela tríade ensino, pesquisa e extensão, embora nem todas as instituições de ensino superior a desenvolva em sua totalidade. No entanto, essa é a referência para que o professor do ensino superior desenvolva sua prática e realize seus processos formativos, que devem levar em consideração as dimensões pessoais, profissionais e institucionais desses professores. Nesse movimento, a formação docente se estabelece como uma das determinações para o fazer profissional docente.

Isso significa afirmar que os processos formativos do professor do ensino superior, no movimento do seu desenvolvimento profissional, estão vinculados às transformações de suas relações pessoais, profissionais e institucionais.

A particularidade que apreendemos no movimento inicial da análise sobre as significações desses professores foi a significativa mediação das suas vivências na educação básica para o desenvolvimento da atividade docente no ensino superior. Essas vivências mediaram o aparecimento de novas necessidades, cujas motivações orientaram 0 desenvolvimento de ações que produziram transformações nas maneiras de pensar, sentir e agir desses professores, em relação à sua atividade docente no ensino superior. 
Por fim, este texto nos sugere novos estudos a fim de compreendermos as particularidades das relações pessoais, profissionais e institucionais do professor do ensino superior e a representação destas na manifestação do desenvolvimento profissional docente.

\section{Referências}

ABRAHÃO, M. H. M. B. Metamemória-memórias: memoriais rememorados/narrados/refletidos/ em seminário de investigação-formação. In: PASSEGGI, M. C.; BARBOSA, T. M. N. (org.). Memória, memoriais: pesquisa e formação docente. Natal-RN: EDUFRN; São Paulo: Paulus, 2008. (Coleção Pesquisa (Auto)biográfica $\infty$ Educação).

ALMEIDA, M. I. Formação do professor do ensino superior: desafios e políticas institucionais. 1. ed. São Paulo: Editora Cortez, 2012 (Coleção Docência em formação).

ARAÚJO, J. C. S. Pedagogia universitária: gênese filosófico-educacional e realizações brasileiras no século XX. Linhas Críticas, v. 14, n. 26, jan-jun, 2008, pp. 25-42. Disponível em: http://www.redalyc.org/articulo.oa?id=193517442007. Acesso em: 31 mar. 2018.

ARAUJO, F.A.M.; CARVALHO, M.V.C. (2020). As significações do professor do ensino superior sobre as ações constitutivas do estudo na Pós-graduação em Educação. MovimentoRevista de Educação, Movimento-Revista de Educação, Niterói, ano 7, n. 14, Edição Especial, pp.181-208, 2020. Disponível em: https://doi.org/10.22409/mov.v7i14.42698

ARAUJO, F. A. M. Eu me desenvolvo, tu te desenvolves, nós nos desenvolvemos: o desenvolvimento profissional do professor do ensino superior que vivenciou estudos na Pósgraduação em Educação. 2019. 314f. Tese (Doutorado em Educação) - Programa de PósGraduação em Educação, Universidade Federal do Piauí, Teresina-PI, 2019. Disponível em: https://doi.org/10.29327/4324275

BATISTA, M.M.C.; MEIRELES, J.C.D. Estratégias e metodologias de apoio ao desenvolvimento pessoal, profissional e funcional. Revista de Administração Pública, Rio de Janeiro. abr./jun. 1984. Disponível em:

http://bibliotecadigital.fgv.br/ojs/index.php/rap/article/viewFile/10560/9558. Acesso em: 02 fev. 2019.

BOLZAN, D. P. V.; ISAIA, S. M. A.; MACIEL, A.M.R. Formação de professores: a construção da docência e da atividade pedagógica na Educação Superior. Revista Diálogo Educacional, Curitiba, v. 13, n. 38, pp. 49-68, jan./abr. 2013. Disponível em: https://periodicos.pucpr.br/index.php/dialogoeducacional/article/view/7817. Acesso em: 11 mar. 2018.

BRASIL. Lei n. 9.394 de 20 de dezembro de 1996. Lei de Diretrizes e Bases da Educação Nacional. Diário Oficial da União, Brasília, DF, 23 dez. 1966. p. 27833-41.

BROILO, C. L.; FORSTER, M. M. S.; FAGUNDES, M. C. V. É possível construir a docência universitária? Linhas Críticas, v. 15, n. 29, jul-dez, 2009, pp. 233-249. Disponível em: http://www.redalyc.org/articulo.oa?id=193514388004. Acesso em 05 fev. 2018. 
FÁVERO, A. A.; TAUCHEN, G. Docência na educação superior: tensões e possibilidades de gestão da profissionalização. Acta Scientiarum: Education, v. 35, n. 2, pp. 235-242, 28 maio 2013. DOI 10.4025/actascieduc.v35i2.20074.

FRANCO, M. A. S. Pedagogia e prática docente. São Paulo: Cortez, 2012.

FORMOSINHO, J.; FERREIRA, F.I. Concepções de professor: diversificação, avaliação e carreira docente. In: Formação de professores: aprendizagem profissional e ação docente. Porto: Porto Editora, 2009.

GATTI, B. Educação, escola e formação de professores: políticas e impasses. Educar em Revista, Curitiba, n. 50, p. 51-67, out./dez. 2013. Editora UFPR. Disponível em: http://www.scielo.br/pdf/er/n50/n50a05.pdf. Acesso em: 20 fev. 2019.

GUARNIERI, Maria Regina. O início na carreira docente: pistas para o estudo do trabalho do professor. In: GUARNIERI, Maria Regina (Org.). Aprendendo a ensinar: o caminho nada suave da docência. 2 ed. Campinas: Autores Associados, 2005. pp.05-24.

HUBERMAN, M. O ciclo de vida profissional dos professores. In: NÓVOA, A. Vidas de professores. Porto: Porto Editora, 2013.

ISAIA, S. M. A. Formação do professor do ensino superior: tramas na tessitura. In: MOROSINI, M.C. (org.). Enciclopédia de Pedagogia Universitária, v. 1. Porto Alegre, FAPERGS/RIES. 2003.

ISAIA, S. M. A; BOLZAN, D. P. V. Compreendendo os movimentos construtivos da docência superior: construções sobre pedagogia universitária. Linhas Críticas, v. 14, n. 26, jan-jun, 2008, p. 25-42. Disponível em:

http://www.redalyc.org/articulo.oa?id=193517442005. Acesso em: 05 fev. 2018.

LEONTIEV, A. O desenvolvimento do psiquismo. Lisboa: Horizonte Universitário, 1978.

LIBÂNEO, J.C. Formação de Professores e Didática para Desenvolvimento Humano. In:

Educação \& Realidade, Porto Alegre, Ahead of print, 2015. Disponível em:

http://dx.doi.org/10.1590/2175-623646132. Acesso em: 03 abr. 2018.

LEFEBVRE, H. Lógica formal lógica dialética. Rio de Janeiro: Civilização Brasileira, 1991.

MOROSINI, M.C. Docência universitária e os desafios da realidade nacional. In:

MOROSINI, M.C. Professor do Ensino Superior: identidade, docência e formação. Brasília: Plano Editora, 2001.

MOROSINI, M.C. Enciclopédia de Pedagogia Universitária - Glossário v. 2. Brasília: INEP/RIES, 2006. 
OLIVEIRA, C. C. Práticas de formação e formação prática. 2008. Disponível em: http://200.189.113.133/det/modules/conteudo/conteudo.php?conteudo=61. Acesso em: 28 nov. 2018

PIMENTA, S. G.; ANASTASIOU, L. G. C. Docência no ensino superior. São Paulo: Cortez, 2014 (Coleção Docência em formação).

SCHAFF. A. O marxismo e o indivíduo. Rio de Janeiro: Civilização Brasileira, 1967.

TORRES, A. R. A Pedagogia Universitária e suas relações com as políticas institucionais para a formação de professores da Educação Superior. 2014. 294 f. Tese (Doutorado em Educação). Universidade de São Paulo - Faculdade de Educação. São Paulo, 2014.

VÁSQUEZ, A. S. A filosofia da práxis: unidade da teoria e da prática. In: MAGALHÃESVILHENA, V. Práxis: a categoria materialista de prática social. Lisboa: Livros Horizonte, 1980.

VIEIRA PINTO, Sete lições sobre educação de adultos. São Paulo, Cortez, 16. ed., 2010.

VIGOTSKI, L.S. A construção do pensamento e da linguagem. São Paulo: Martins Fontes, 2009.

VIGOTSKI, L.S. Quarta aula: a questão do meio na Pedologia. Tradução: Márcia Pileggi Vinha. In: Psicologia USP, v. 21, n. 4, out-dez, 2010, pp. 681-701, 2010.

VIGOTSKI, L.S. Sete aulas de L.S. Vigotski sobre os fundamentos da pedologia.

Organização e tradução: Zoia Prestes, Elizabeth Tunes. 1. ed. Rio de Janeiro: E-papers, 2018.

Recebido em agosto de 2021.

Aprovado em outubro de 2021. 